\title{
POSTGRADUATE SCHOOL OF APPLIED DYNAMICS AT THE UNIVERSITY OF EDINBURGH
}

TT is characteristic of modern technology that, 1 while it calls for an ever-increasing number of graduates who have undergone a wide general training in engineering, it calls in addition for a limited number of specialists with a deep knowledge of the theory and techniques of some particular field as well as a wide general knowledge of engineering. With curricula already overcrowded, undergraduate courses cannot-and should not-produce these specialists, and the need is being met by the founding of postgraduate schools within the universities, each dealing with some particular field.

The Postgraduate School of Applied Dynamics has been planned within the Department of Engineering at the University of Edinburgh with this need in mind. 'The subject of 'applied dynamics', which has been defined as 'the study of solids in motion', may appear to be restricted, but modern developments in highspeed machinery, control systems and inertial navigation--to take a few examples-have emphasized the need for the practical application of advanced theory and techniques in this subject.

Thus the main function of the Postgraduate School of Applied Dynamics is to be its diploma course, for which graduates in mathematics and physics, as well as engineering, are eligible ; the first course will last from October 1957 until June 1958. There are to be formal lecture courses on the fundamental mechanics of solids and relevant analytical methods and on their application to vibration problems, control systems and the dynamies of gyroscopes, as well as other related subjects. Often advanced published work in these subjects is not easily available or assimilable, and one of the aims of the course will be to present such work with emphasis on practical applications. Moreover, in addition to his attendance at the lecture courses, each student will undertake a limited research investigation in a field of applied dynamics related to his particular interests. 'The Engineering Department has a good library, and its content of books and periodicals pertaining to applied dynamics is being increased.
The course should be of particular value to men who are already in industry or in research organizations and so have some knowledge of the problems likely to confront them, although new graduates will also be accepted. It is believed that the interchange of ideas between students of different industrial backgrounds will be a most valuable feature of the course. The difficulty of releasing men of the right calibre is appreciated, but it is hoped that the long-term advantages of doing so will be apparent.

British industry has contributed $£ 20,000$ to endow the new School at Edinburgh, which is to be accommodated at first within the existing engineering building. A large extension to the Department of Engineering is planned and accommodation in it has been allocated to the School, so that it will be possible to use industry's donation mainly for equipment. There is a small full-time teaching staff, but lectures will also be given by other members of the Department, and in particular by members of the existing Postgraduate School of Electronics and Radio, as the two Schools have sub. jects of common interest. The staff of the Electronies School will also be available for advice on problems of electrical measurement and instrumentation.

Research on dynamical problems has been conducted under Prof. R. N. Arnold in the Engineering Department for some years, and out of this the new School has grown. With the increase in the number of staff interested in dynamical problems and, it is hoped, a corresponding increase in research students, the scope and volume of research in applied dynamics should grow. This previous research experience forms a base on which to build the school and has helped in the planning of the new lecture courses. These courses must be sufficiently flexible to cover the requirements of students from various industries, and naturally requirements will change as the subject advances, but it is thought that the syllabus as planned contains topics that are directly relevant to the dynamical problems of many different branches of industry.
G. B. Warburton

\section{ELECTRICAL METHOD FOR DETECTION OF EARLY CANCEROUS GROWTH OF THE SKIN}

\author{
By Prof. N. MELCZER and DR. J. KISS \\ Department of Dermatology and Venereology, University of Fécs
}

\begin{abstract}
$\mathrm{O}^{\mathrm{v}}$ $\mathrm{N}$ passing a direct current by means of nonpolarizing electrodes through living tissue the charge of the Helmholtz double (opposite potential) layer is probably increased at cell junctions. In addition, diffusion potentials will arise because the cell membrane is not uniformly permeable to every ion and because the ions have different mobilities. As a result the system builds up a counter electromotive force due to polarization which will diminish the effective d.c. voltage. Because of the generation of a polarization countercurrent the resistance of normal
\end{abstract}

skin is apparently high. But this is not a true ohmic resistance and it has therefore been called a 'pseudo. resistance'. While studying electrodermatograms, that is, pseudo-resistances induced in different skin conditions, it has been found that the polarization countercurrent of dermal cancers in living persons fails to appear or cannot be obtained in its full strength, a phenomenon which can be demonstrated with a microammeter.

As early as 1918, Clowes ${ }^{1}$ claimed that, in general, malignant tumours show a lower electric resistance 